\title{
Machine Learning on Emotional Intelligence and Work Life Balance
}

\author{
P. Julia Grace, Ph.D. \\ Assistant Professor and Research Supervisor \\ Department of Computer Science \\ JBAS College for Women, Chennai, Kodaikanal
}

\author{
N. Nasreen Banu \\ M. Phil. \\ Computer Science Scholar \\ Mother Teresa Women's University
}

\begin{abstract}
Emotions are an essential part of our biological makeup, and every morning they march into the office with us and influence our behavior. Our ultimate focus is on Emotional Intelligence (EI) and we combine with data mining technology. Dealing with employees emotions using different machine learning techniques is one of the phenomenal researches in today's world. Here, we examine how far the employees are conscious of their own self and found the ideas and views of an individual about themselves and others. Without proper knowledge about their personality it will be very difficult for an individual to manage their own emotions. This study aims at finding out the individual abilities to manage their emotions in order to perform well. The clustering and classification techniques are applied on same dataset of human emotions, which deals with different types of analysis.
\end{abstract}

\section{Keywords}

Emotional intelligence, Stress, Job satisfactions and Productivity

\section{INTRODUCTION}

The main purpose of this research paper is to examine the impact of emotional intelligence on job satisfaction and productivity. If the employees know their own passion, they are able to manage their work more efficiently and productively.

Work life balance is a challenging issue for the employees and has attracted the attention of researchers. It is defined as a satisfactory level of involvement between the multiple roles in a person's life. Managing the boundary between home and workplace is becoming more challenging. This paper aims to gain knowledge about the emotional intelligence level of employees and suggest ways to enhance the emotional intelligence of the employees, with the collected data. This helps them to analysis their own self and improves them. The sample size chosen has covered only a small portion of the whole population.

\subsection{Objectives}

Emotional intelligence consists of five factors: Knowing one's emotions, managing emotions, motivating one, recognizing emotions in others, and handling relationships Goleman (1995). The main objective of the study is to determine the Emotional Intelligence of the Employees:

\footnotetext{
$\checkmark \quad$ Evaluating self - awareness of the employees

$\checkmark$ Analyzing motivational level of the employees

$\checkmark$ Analyzing sensitivity of the employees

$\checkmark \quad$ Evaluating ability of the employees
}

\section{$\checkmark \quad$ Determining influence of the employees}

\subsection{Emotional Intelligence}

According to Daniel Goleman [1], the oldest centers of the human brain, those responsible for feelings, are also responsible for managing ourselves and our social skills. These are skills that are contained in the genetic development of people and serve for the survival and adaptation of mankind. The emotional part of the brain perceives the world differently than the reasonable part. This conclusion brings new perspective on an enormous gap between cognition and emotion. Some skills are just cognitive, such as analytical thinking and technical skills. Some of them are a mixture of combined parts between cognition and emotion; this is called emotional intelligence (Goleman, 2001, p. 18-36).

Emotional intelligence can therefore be defined as the ability to recognize and adjust our emotions that trigger our responses with certain situations or people. We can learn how to gain control over our responses and actively participate in forming our social skills. Emotional intelligence - the ability to manage ourselves and our relationships - consists of four fundamental capabilities: self-awareness, self-management, social awareness, and social skill. Each capability, in turn, is composed of specific sets of competencies (Goleman, Boyatziss\& McKee, 2002, 263-265).

Emotional intelligence (EI) [1] refers to the ability to perceive, control and evaluate emotions. Some researchers suggest that emotional intelligence can be learned and strengthened, while others claim it is an inborn characteristic. Emotions in the workplaceplay a major role in how an entire organization communicates within itself and to the outside world. The consequences of emotional states in the work area, both behavioral and attitudinal, have substantial significance for individuals, groups, and society. Positive emotions in the workplace help employees obtain favorable outcomes including achievement, job enrichment and higher quality. Negative emotions, such as fear, anger, stress, sadness and guilt,however increase the predictability of workspace devianceand how the outside world views the organization. The four branches of Emotional Intelligence are

1. Perception Appraisal and Expression of Emotion.

2. Emotional Facilitation of Thinking.

3. Emotional Understanding and Analyzing Emotions; Employing Emotional Knowledge.

4. Emotional Management. The main identifying characteristics of Emotional Maturity are made possible by the Emotional Intelligence component.

1. Self-awareness: Recognize and understand own moods and motivations and their effect on others. To achieve this state, one must be able to monitor her/his own emotional state and identify own emotions. 
2. Self-Regulation: Controlling the impulses - instead of being quick to react rashly, one can control their emotions and think before responding to express appropriately.

3. Empathy: The ability to understand another person's emotional reaction. This is only possible when one has achieved self-awareness - as one cannot understand others until they understand themselves.

4. Social Skills: Identifying social cues to establish common view manage relationships and build networks.

\subsection{Data Mining Aspects}

Machine Learning aims to mimic intelligent abilities of humans by machines. It is the study of computer algorithms that improve automatically through experience and its primary goal is to derive general patterns from a limited amount of data. Machine Learning is closely related to Data Mining, Biology or Neurobiology, Formal Languages and Automata, Pattern Recognition, Graph Theory, Artificial Intelligence, Neural Networks, Statistics, Economics, Organizational behavior and Evolution. Few widespread applications of Machine Learning are illustrated in fig. 1. Here, in this study we focus on the data mining part.

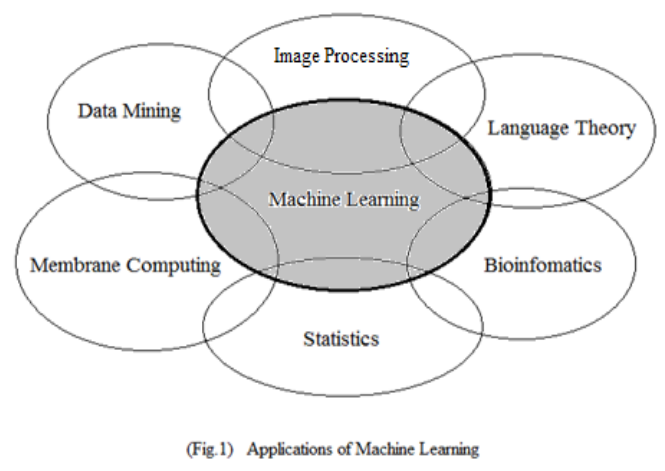

Data mining, an extraction of knowledge from large volumes of data, uses sophisticated mathematical algorithms to segment the data and evaluate the probability of future events. There are several major data mining techniques are useful for discovering the patterns such as association, classification, clustering, prediction, sequential patterns, decision trees, etc. The general functional diagram is as follows

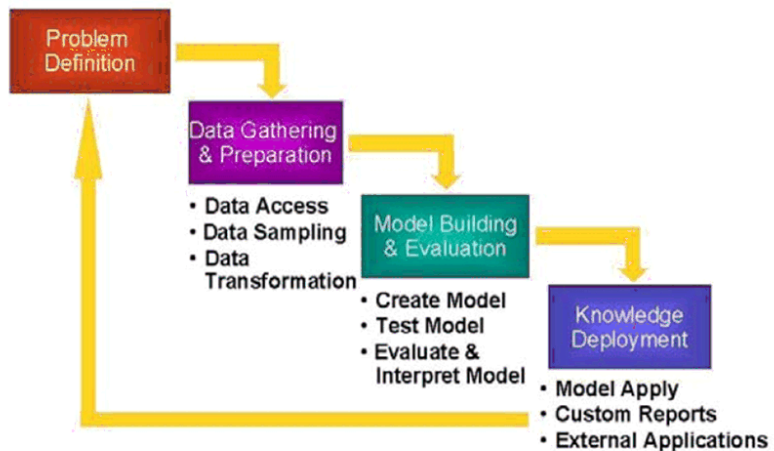

We follow two data mining algorithms - Classification and Clustering in this study.

Classification - It is a classic data mining technique based on machine learning. It is used to classify each item in a set of data into one of predefined set of classes or groups. Classification method makes use of mathematical techniques such as decision trees, linear programming, neural network and statistics.

Clustering - It is a data mining technique that makes meaningful or useful cluster of objects which have similar characteristics using automatic technique. The clustering techniques define the classes and puts objects in each class.

\section{ANALYSIS OF DATA}

Analysis and interpretation of collected data is the heart of this work. Only after analysis one can arrive at the findings with the related problem identified. This findings which have been arrived after analysis and interpretation helps to find out the hidden solution for the problem and give most appropriate suggestions for overcoming problems.

Data is analyzed using Classification and Clustering techniques.Analysis of data through these techniques has been achieved with the help of Weka tool.The SPSS software has also been used to analyze and depict the collected data via various tables and charts.Questions were framed based on self awareness, self regulation, empathy and political awareness to collect data on emotional intelligence by asking the respondents to give their opinion on the following questions.

\subsection{Interpretation}

The following tables are constructed based on the data collected through questionnaire.

Table 2.1 - I understand my own abilities

\begin{tabular}{|l|r|r|r|r|}
\hline & Frequency & Percent & $\begin{array}{c}\text { Valid } \\
\text { Percent }\end{array}$ & $\begin{array}{c}\text { Cumulative } \\
\text { Percent }\end{array}$ \\
\hline Strongly & 3 & 6.0 & 6.0 & 6.0 \\
Disagree & & & & \\
Disagree & 4 & 8.0 & 8.0 & 14.0 \\
Neither/Nor & 10 & 20.0 & 20.0 & 34.0 \\
Agree & 21 & 42.0 & 42.0 & 76.0 \\
Strongly Agree & 12 & 24.0 & 24.0 & 100.0 \\
Total & 50 & 100.0 & 100.0 & \\
\hline
\end{tabular}

From Table 2.1, we can interpret that that $6.0 \%$ of them valid strongly disagree, $8.0 \%$ of them valid disagree, $20.0 \%$ of them valid neither/nor agree, $42.0 \%$ of them valid agree, $24.0 \%$ of them valid strongly agree. The following chart illustrates this concept.

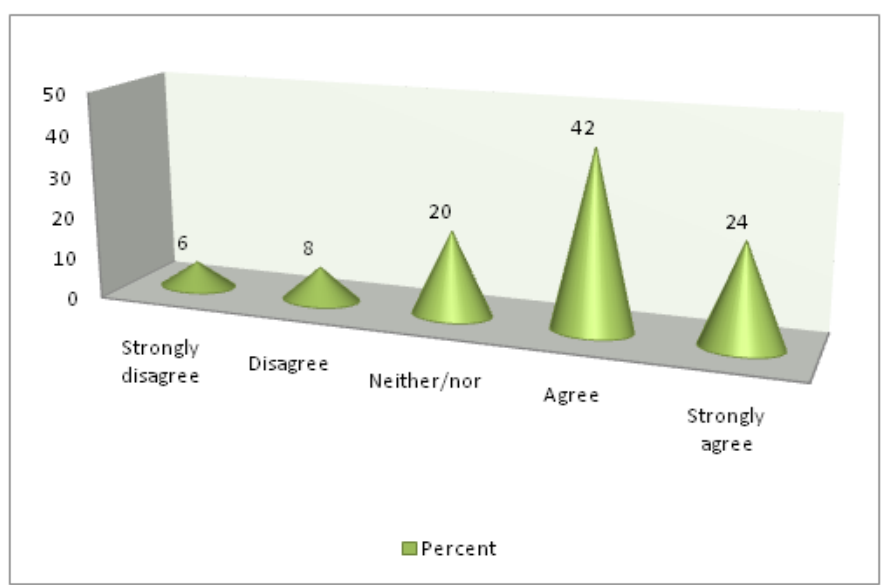


Table 2.2 - I am aware of my strong and weak points

\begin{tabular}{|l|r|r|r|r|}
\hline & Frequency & Percent & $\begin{array}{c}\text { Valid } \\
\text { Percent }\end{array}$ & $\begin{array}{l}\text { Cumulative } \\
\text { Percent }\end{array}$ \\
\hline Disagree & 2 & 4.0 & 4.0 & 4.0 \\
Neither/Nor & 5 & 10.0 & 10.0 & 14.0 \\
Agree & 18 & 36.0 & 36.0 & 50.0 \\
Strongly & 25 & 50.0 & 50.0 & 100.0 \\
Agree & 50 & 100.0 & 100.0 & \\
Total & & & \\
\hline
\end{tabular}

From Table 2.2, we can interpret that $4.0 \%$ of them disagree, $10.0 \%$ of them valid Neither/Nor agree, $36.0 \%$ of them validagree, $50 \%$ of the valid strongly agree. The following chart explains this concept.

\section{percent}

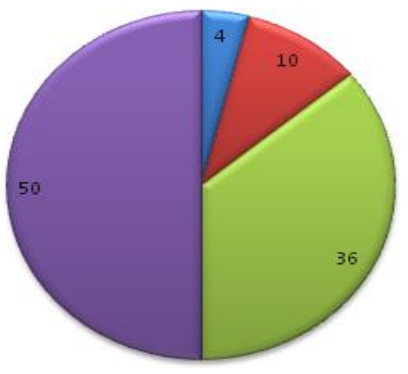

$$
\begin{aligned}
& \text { Disagree } \\
& \text { Neither/nor } \\
& \text { Agree } \\
& \text { MStrongly agree }
\end{aligned}
$$

\section{INFERENCES}

Evaluation on the given data is summarized using Weka tool. The inferences based on the usage of both the algorithms are as follows:

\subsection{Classification}

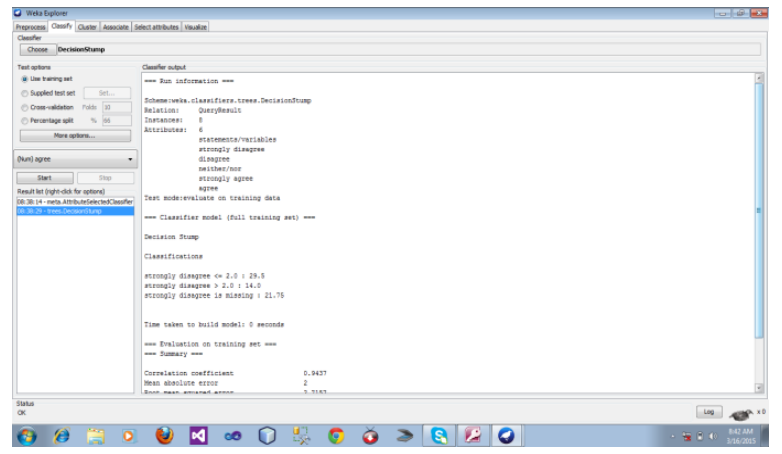

When Classifying using decision tree method, wechoose test option as training set based on the responses given by the employees for questionnaire statements. The above table is built using weka tool where the total number of attribute take are 6 and instance for those attribute is taken as 8 . The test mode isevaluated on the training data. The average of the total number of employees who strongly disagree using the Classifier model (full training set) is 29.75. The average of the total number of employees who doesn't disagree using the Classifier model (fulltraining set) is 14.0. Time taken to build model is 0 second. In the same way we calculate for the remaining attributes. Evaluation on training set is summarized by the tool as follows: Correlation coefficient 0.9457 , Root mean squared error 2, Relative absolute error 25.8065, Root relative squared error 33.0697, Total Number of Instances 8 .

\subsection{Clustering}

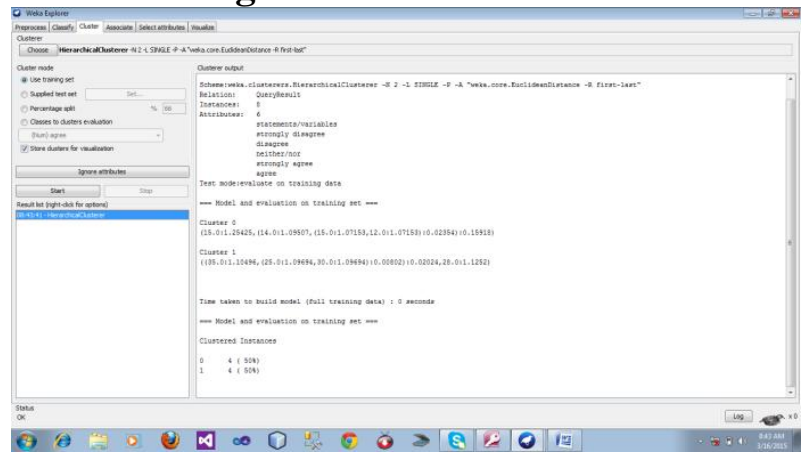

Evaluation on the given data is summarized using Weka tool for clustering as follows: scheme: weka. clusterers. Hierarchical Clusterer- N2-LSINGLE-P-A"weka. core. Euclidean instance - $\mathrm{R}$ first-last" where the relation is query result and the number of instance are 8 and the attributes are 6 for the feedback values provided by the employees and the Test mode is evaluate on training data. Model and evaluation on training set whereas on

\section{Cluster0}

(15.0:1.25425,(14.0:1.09507,(15.0:1.07153,12.0:1.07153):0.0 2354):0.15918)

Cluster 1

((35.0:1.10496,(25.0:1.09694,30.0:1.09694):0.00802):0.02024 ,28.0:1.1252)

time taken to build model (full training data) : 0 seconds

Model and evaluation on training set

Clustered Instances

$04(50 \%)$

$14(50 \%)$

Here, the above result is divided into two folds. Based on given values the above clustered instances show the $\%$ rate for cluster 0 and cluster 1 . The execution time taken by Classification and Clustering algorithms is 0 seconds and they provide similar result for the given data. Both the algorithms used provide the same results.

\section{CONCLUSION}

A next step to increase the reliability of the results is repeating the research study usinga larger sample. Emotional regulation and mood play a key role in anybody's academic success. This emotional change causes relational conflicts. Emotional variation detection can help to control the negative emotions. This paper explored emotional variation of employees using clustering and classification techniques, by using the same dataset. Usually, older people are slightly more likely to be higher in emotional intelligence. The finding suggests emotional intelligence is a developing ability; it is likely that accumulated life experiences contribute to EQ. Through this study, it is concluded that emotional intelligence has greater impact on performance of employees. Secondly, an emotionally intelligent organization is based on an organizational strategy to improve business performance. 


\section{REFERENCES}

[1] Goleman, D., 1998. Working with emotional intelligence. New York: Bantam Books.

[2] Morrison, E.W., 1993. Longitudinal study of the effects of information seeking on newcomer socialization. J. Appl. Psychol., 78: 173-183.

[3] Goleman, D. (1997). Emotional Intelligence: Why It Can Matter More Than IQ. Ljubljana: Mladinskaknjiga.

[4] Svetlana Lazovic, "The role and importance of emotional intelligence in Knowledge management", Management Knowledge and learning, Intl Conf. 2012

[5] MadihaSahdat et al,"Emotional Intelligence and Organizational Productiviy: A Conceptual Study", World Applied Sciences Journal 15 (6): 821-825, 2011

[6] Thi Lam, L. and S.L. Kirby, 2002. Is Emotional Intelligence and advantage? An exploration of the impact of emotional and general intelligence on individual performance. The J. Social Psychol., 142(1): 133-143.

[7] P. Julia Grace and Suman Sharma, "An analytical approach on Chennai road accidents-Machine Learning approach", IJSC, March 2015.

\section{AUTHOR'S PROFILE}

Julia Grace P. received her B.Sc., Computer Science in 2000 and MCA in 2003, both from Manonmaniam Sundaranar University. She got the University FIRST Rank in MCA. She obtained her B.Ed., in 2004 from University of Madras, M.Phil., from Madurai Kamaraj University in 2005 and Ph.D. from Mother Teresa Women's University in 2013 . Right now, she is Assistant Professor in Computer Science in JBAS College for Women (Autonomous), Chennai. Until now, she has guided 9 M.Phil scholars, presented 15 papers in National, International Conferences and published 8 research articles in International Journals. Her areas of interest are Artificial Intelligence, System Biology, Machine Learning and Theoretical Computer Science. She is a life member of International Association of Professional Academicians, member of International Association of Engineers, executive board member and review member for few reputed journals.

N. Nasreen Banu is currently doing M.Phil Computer Science in Mother Teresa Women's University, Kodaikanal [Chennai Centre], after completing her M.Sc Computer Science in April 2014 